\title{
BMJ Open Effects of presurgical interventions on chronic pain after total knee replacement: a systematic review and meta-analysis of randomised controlled trials
}

\author{
Jane Dennis (D , ${ }^{1}$ Vikki Wylde, ${ }^{1,2}$ Rachael Gooberman-Hill, ${ }^{1,2}$ AW Blom, ${ }^{1,2}$ \\ Andrew David Beswick (D) ${ }^{1}$
}

To cite: Dennis J, Wylde V, Gooberman-Hill R, et al. Effects of presurgical interventions on chronic pain after total knee replacement: a systematic review and meta-analysis of randomised controlled trials. BMJ Open 2020;10:e033248. doi:10.1136/ bmjopen-2019-033248

- Prepublication history and additional material for this paper are available online. To view these files, please visit the journal online (http://dx.doi. org/10.1136/bmjopen-2019033248).

Received 30 July 2019 Revised 26 November 2019 Accepted 12 December 2019

Check for updates

(C) Author(s) (or their employer(s)) 2020. Re-use permitted under CC BY. Published by BMJ.

${ }^{1}$ Musculoskeletal Research Unit, Translational Health Sciences, University of Bristol, Bristol, UK ${ }^{2}$ National Institute for Health Research Bristol Biomedical Research Centre, University Hospitals Bristol NHS Foundation Trust and University of Bristol, Bristol, UK

Correspondence to

Dr Jane Dennis;

jane.dennis@bristol.ac.uk

\section{ABSTRACT}

Objective Nearly 100000 primary total knee replacements (TKR) are performed in the UK annually. The primary aim of TKR is pain relief, but $10 \%-34 \%$ of patients report chronic pain. The aim of this systematic review was to evaluate the effectiveness of presurgical interventions in preventing chronic pain after TKR. Design MEDLINE, Embase, CINAHL, The Cochrane Library and PsycINF0 were searched from inception to December 2018. Screening and data extraction were performed by two authors. Meta-analysis was conducted using a random effects model. Risk of bias was assessed using the Cochrane tool and quality of evidence was assessed by Grading of Recommendations Assessment, Development and Evaluation.

Primary and secondary outcomes Pain at 6 months or longer; adverse events.

Interventions Presurgical interventions aimed at improving TKR outcomes.

Results Eight randomised controlled trials (RCTs) with data from 960 participants were included. The studies involved nine eligible comparisons. We found moderatequality evidence of no effect of exercise programmes on chronic pain after TKR, based on a meta-analysis of 6 interventions with 229 participants (standardised mean difference $0.20,95 \% \mathrm{Cl}-0.06$ to $0.47, \mathrm{I}^{2}=0 \%$ ). Sensitivity analysis restricted to studies at overall low risk of bias confirmed findings. Another RCT of exercise with no data available for meta-analysis showed no benefit. Studies evaluating combined exercise and education intervention $(n=1)$ and education alone $(n=1)$ suggested similar findings. Adverse event data were reported by most studies, but events were too few to draw conclusions.

Conclusions We found low to moderate-quality evidence to suggest that neither preoperative exercise, education nor a combination of both is effective in preventing chronic pain after TKR. This review also identified a lack of evaluations of other preoperative interventions, such as multimodal pain management, which may improve long-term pain outcomes after TKR.

PROSPERO registration number CRD42017041382.
Strengths and limitations of this study

- This systematic review evaluates recent evidence of the effectiveness of presurgical interventions in preventing chronic pain after total knee replacement.

- Synthesis of adverse events data was not possible.

- We only included studies that completed intervention delivery during the preoperative period and did not include studies that evaluated interventions that began in the preoperative period but extended into the perioperative and postoperative period.

\section{BACKGROUND}

Osteoarthritis is the most common condition that affects the knee joint and causes considerable pain and disability. Effective treatments noted in guidelines include pain medications, exercise and weight loss when appropriate. ${ }^{12}$ If symptoms do not respond to pharmacological and conservative treatments, people may receive a total knee replacement (TKR). Annually in the UK, nearly 100000 primary TKRs are performed, ${ }^{3}$ and in the USA in 2010, about five million people were estimated to be living with a TKR. ${ }^{5}$ Outcomes are good for many, but a systematic review found that $10 \%-34 \%$ of patients report unfavourable long-term pain outcomes at between 3 months and 5 years after $\mathrm{TKR}^{6}$ which is associated with dissatisfaction with the outcome of surgery. ${ }^{78}$

Some patient factors are associated with poor long-term pain outcomes. Using structural equation modelling, Sayers and colleagues demonstrated that pain during the presurgical period, particularly on movement, is strongly associated with chronic postsurgical pain, and a potentially important target for intervention. ${ }^{9}$ Other presurgical risk factors for pain identified in multivariable analyses in representative populations include: poorer physical 
function, body mass index $\geq 35 \mathrm{~kg} / \mathrm{m}^{2}$ and poor general mental health. ${ }^{10}$ With knowledge of risk factors for chronic pain, there is the potential for targeting care to those at high risk or for risk factor modification. ${ }^{10} 11$ While many presurgical interventions focus on preparing the patient for the procedure and hospital stay, reducing perioperative pain and facilitating early mobilisation and recovery, ${ }^{10}$ their impact on the key outcome of chronic pain remains to be established. This is achievable through high quality, adequately powered randomised controlled trials with long-term follow-up for patient-related pain outcomes and ultimately through well-conducted systematic reviews with thorough consideration of sources of bias that may influence study results.

In a systematic literature search of MEDLINE, Embase, PsycINFO, CINAHL and The Cochrane Library on 18 December 2018, we identified 36 systematic reviews of preoperative interventions in TKR. Twenty-five of these had searches conducted more than 5 years previously, ${ }^{10-35}$ and nine exclusively reported short-term outcomes (3 months or less after surgery). ${ }^{36-44}$ Two more recent reviews considered the outcome of long-term pain $^{45}{ }^{46}$ but neither had a registered protocol. Chesham and Shanmugam identified two randomised controlled trials in their search window (2004-2014) that reported no difference in pain at 6 months after surgery in patients randomised to exercise or control. ${ }^{45}$ Wang and colleagues identified three randomised controlled trials of preoperative exercise-based interventions in patients waiting for knee or hip replacement that reported long-term pain and were published up to November $2015 .^{46}$ No difference in pain outcome was apparent at 6 months or longer in patients receiving intervention or control.

In this systematic review and meta-analysis, we assessed the effectiveness of preoperative interventions in preventing chronic pain in patients receiving TKR. Previous reviews have largely focused on specific interventions but we have opted for a temporal framework and sought to include any intervention conducted before surgery. This review is part of a broad suite of reviews considering the timing of intervention throughout the TKR care trajectory. ${ }^{47} 48$

\section{METHODS}

The protocol for this systematic review was registered with PROSPERO. ${ }^{49}$ We formulated the research question according to the participants, intervention(s), comparator(s), outcomes (PICO) principle ${ }^{50}$ and used methods based on those recommended by Cochrane.$^{51}$ Reporting has been in accordance with the Preferred Reporting Items for Systematic Reviews and Meta-Analyses (PRISMA) guidelines, ${ }^{52}$ and a checklist is included in the online supplementary appendix.

\section{Patient and public involvement}

Before starting the review, we held a meeting with stakeholders and patient representatives and discussed inclusion criteria and outcomes. Areas of potential relevance for presurgical intervention were highlighted, specifically exercise, education, psychological therapies, weight management, nutritional supplements, management of comorbidities and pain management with intraarticular injections. The importance of patient-reported pain as an outcome after TKR was emphasised. A musculoskeletal patient and public involvement forum has discussed the review and will advise on plain language summaries and dissemination. ${ }^{53}$

\section{Types of studies}

To limit selection bias, we included only randomised controlled trials. Studies reported only as abstracts or unobtainable as full text copies were excluded. Language was not an exclusion criterion.

\section{Participants}

Eligible participants were adults on the waiting list for TKR, up until the point of admission for surgery.

\section{Interventions}

Preventive interventions (pharmacological or nonpharmacological) delivered during the presurgical period were included. Studies where delivery of the intervention extended into the postoperative period were excluded.

\section{Comparator group}

Comparator group participants included those who had received usual care or an alternative intervention.

\section{Outcomes}

In preference, we considered patient-reported jointspecific pain intensity, typically measured using pain domains of the Oxford Knee Score,${ }^{54}$ Western Ontario and McMaster Universities Osteoarthritis Index $\left(\right.$ WOMAC) ${ }^{55}$ or Knee injury and Osteoarthritis Outcome Score (KOOS $)^{56}$ at 6 months or longer after knee replacement. We selected these outcomes in preference to pain components of Knee Society's Clinical and Functional Scoring System (KSS) ${ }^{57}$ and Hospital for Special Surgery Knee Score (HSS ${ }^{58}$ in which pain assessment is limited to one or two questions on intensity ${ }^{59}$ and relies on clinician assessment which may not reflect the views of patients. ${ }^{60}$ The choice of outcome timing reflects the time when, for many, pain levels have optimised.$^{61}$ If joint specific measures were not available, then we planned to use pain dimensions from quality of life measures including Short Form 36 Health Survey (SF-36) ${ }^{62}$ and Short Form 12 Health Survey. ${ }^{63}$ Had neither joint-specific nor generic pain outcomes been available, we planned to use data for pain measured using a Visual Analogue Scale (VAS) or Numerical Rating Scale. When no patient-reported outcome measure was reported, we used pain data from surgeon-assessed scores. When discrete pain data were unavailable, we reported overall data that included those relating to pain, typically in combination with function and other factors. 
Where data were available, we planned to report proportions of patients with a favourable pain outcome (eg, 'no worse than mild pain') as recommended in clinical trials ${ }^{64}$ and systematic reviews. ${ }^{65}$

Data on all adverse events were extracted and summarised narratively. Our focus was on adverse events related to the intervention, although we also report those related to surgery.

\section{Study design}

Randomised controlled trials of interventions commencing and completing within the presurgical period, with follow-up at 6 months or longer after surgery for TKR, were identified and assessed for eligibility. Authors reporting long-term outcomes of any type (typically, function only) were contacted to check whether pain outcome data were also available; those reporting aggregated data for hip replacements together with knee replacements were also contacted. Studies meeting these criteria and reporting pain data or composite scores including pain were included.

\section{Database searches}

We established a database of all randomised controlled trials in knee replacement, in preparation for a suite of systematic reviews in chronic pain after TKR ${ }^{4748}$ Relevant trials were identified through searches (last updated on 18 December 2018) in: MEDLINE, Embase and PsycINFO on OvidSP; CINAHL on EBSCOhost; and The Cochrane Library. The search strategy as applied in MEDLINE is shown in online supplementary appendix. Within this resource, we searched for interventions conducted in the presurgical setting.

Citations and reference lists of key reviews and randomised trials were checked in ISI Web of Science. The ISRTN registry on BioMed Central was searched for ongoing randomised trials which were then checked for subsequent publication. No language restrictions were applied, and data from potentially relevant non-English language articles were extracted and translated to establish eligibility. Studies reported only as abstracts or that we were unable to acquire as full text copies using interlibrary loans or author contact were excluded.

\section{Study screening and data extraction}

Records identified by searches were imported into Endnote V.X9 (Thomson Reuters). An initial screen for potential eligibility was undertaken by one review author (JD) with articles excluded only if clearly irrelevant. Typically, these were studies in osteoarthritis with no surgery, arthroscopy only or surgery involving joints other than the knee. Subsequently, abstracts and full text articles were screened independently by two review authors. After consensus, reasons for exclusion were recorded.

Data from relevant randomised trials were extracted by one review author onto forms which were tested and refined before use. Microsoft Excel was used to record abbreviated information, specifically on: country where study was conducted; dates of recruitment; participant characteristics (indication, age, sex); inclusion and exclusion criteria; intervention and control content; setting, timing, duration and intensity of intervention; follow-up data collection (including loss to follow-up); instruments used to collect data on pain; outcome data including pain and adverse events. Data extracted were checked against source material by a second review author.

Group means and SDs of pain outcome measures were recorded at the longest follow-up interval. Data with which to calculate proportions of patients with a poor outcome, however defined, were sought. Authors were contacted for unpublished data. Details of adverse events of any type were extracted.

\section{Risk of bias within included studies}

Potential sources of bias were assessed using the Cochrane risk of bias tool ${ }^{66}$ by two review authors (JD and ADB) working independently; disagreements were adjudicated by a third (VW). We present analyses where possible showing data from all relevant studies for a given outcome, but also conducted sensitivity analyses excluding studies assessed to be at overall high risk of bias.

\section{Data analysis}

When studies reported pain outcome data, these were presented and pooled where possible, using Review Manager V.5.0. ${ }^{67}$ As the control group in one study was shared by two active interventions, the sample size in meta-analysis was halved for the control group, to preserve independence of findings. ${ }^{51}$ Results are presented for one comparison in the form of standardised mean differences (SMDs), as instruments used to measure outcomes varied.

A random effects model was planned, due to anticipated heterogeneity as described below. A sensitivity analysis excluding those comparisons for which we had imputed data and/or studies we had assessed as being at overall high risk of bias was conducted. At protocol stage, ${ }^{49}$ we planned to generate funnel plots, if ten or more studies with similar interventions and controls were identified, as a method of estimating the risk of publication bias. In the event, data were not sufficient to do so.

Heterogeneity between studies (considering both magnitude and direction of effect) was assessed using visual inspection of the graph and the $\mathrm{I}^{2}$ statistic. We anticipated sources of heterogeneity justifying subgroup analyses might include format and intensity of intervention; however, statistical heterogeneity proved to be unimportant, and data were insufficient to conduct such analyses.

\section{Grading of Recommendations Assessment, Development and} Evaluation approach to evidence

We used the Grading of Recommendations Assessment, Development and Evaluation (GRADE) approach to assess the quality of the evidence, ${ }^{68}$ specifically study 


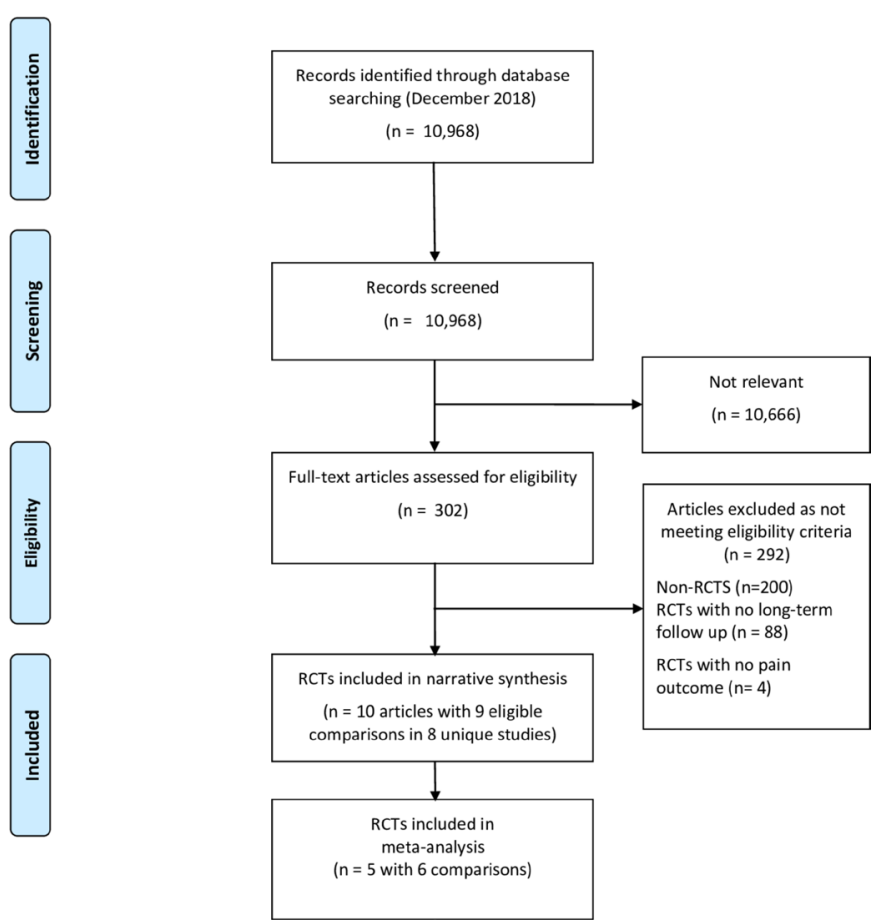

Figure 1 Preferred Reporting Items for Systematic Reviews and Meta-Analyses flow diagram.

limitations, consistency of effect, imprecision, indirectness and publication bias.

\section{RESULTS}

Conduct of the review is summarised in figure 1 . Searches identified 10968 articles. Of these, 302 potentially relevant reports were considered in detail, of which 100 were identified as RCTs (some with multiple publications). Eighty-eight did not follow up participants to a minimum of 6 months. Four trials involving different interventions (smoking cessation, ${ }^{69}$ testosterone injections, ${ }^{70}$ epoetin- $\alpha$ injections ${ }^{71}$ and bacterial screening ${ }^{72}$ followed by decolonisation) did meet eligibility criteria for long-term follow-up, but none of these included outcome data related to pain.

After detailed evaluation, 10 articles reporting data from 8 RCTs $^{73-80}$ were included in the review. These 8 RCTs included data from 960 participants randomised to nine eligible comparisons. The interventions evaluated in the included studies were exercise, education or a combination of both.

Seven publications assessed the impact of a single intervention (exercise (5), education (1) or a combination of both exercise and education (1)) against a no-treatment or attentional control. One publication reported relative effects of two different physical interventions (cardiobased exercise or physiotherapy) against a no treatment control. ${ }^{73}$ We analysed data from the latter publication as two separate studies, dividing the control group during analysis so as to preserve independence of findings. Details of studies, including intervention characteristics, are shown in table 1; risk of bias assessments in figure 2; meta-analysis and sensitivity analyses in figures 3-6. Finally, GRADE assessments of the quality of evidence for these classes of intervention for the outcomes of pain and serious adverse events are shown in table 2.

\section{Overview of study settings, sample sizes and interventions}

Included studies were published between 1996 and 2018. Two studies were conducted in Canada, ${ }^{74}{ }^{80}$ two in the USA, ${ }^{7379}$ and one each in Belgium, ${ }^{77}$ Denmark ${ }^{75}$ Switzerland $^{76}$ and Thailand. $^{78}$ Exercise interventions were delivered within clinics or within the home; education interventions were delivered within clinics in the studies in which it formed part of a composite intervention, or online when it was assessed in isolation.

Samples at recruitment ranged from 30 to 416 participants. The total number of participants involved in studies of exercise alone was 373; exercise and education together, 131; and education alone, 416.

Sample size calculations were reported by most investigators-but only one was based on the primary outcome used within this review (pain at 6 months). Other studies had as their main focus: satisfaction with $\mathrm{TKR}^{80}$; a shortterm reduction of 10 points on the HSS and the reduction of hospital stay by 1 day $^{73}$; the Chair Stand test ${ }^{76}$; a difference of $10^{\circ}$ in passive flexion ${ }^{77}$; an 8-point difference in WOMAC $^{79}$; and a 10-point difference on the KOOS ADL subscale. ${ }^{75}$ The variability in foci among studies makes it difficult for us to estimate a reasonable optimal information size for the review, particularly as some investigators revised their sample size estimates upwards as part of considering limitations of their studies. ${ }^{73} 74$

\section{Participants}

Five studies exclusively recruited participants undergoing TKR for osteoarthritis ${ }^{74}{ }^{76-78} 80$; one permitted those with rheumatoid arthritis ${ }^{73}$; and two included participants undergoing either hip or knee replacement for osteoarthritis, with long-term data reported separately ${ }^{79}$ or in aggregate. ${ }^{75}$ Mean age of participants ranged from 63 to 70 across studies. Gender, where reported, varied greatly, with studies recruiting $17 \%^{78}$ to $60 \%$ women. $^{73}$

\section{Interventions}

Seven interventions assessed within six studies $^{73} 75-79$ were exercise-based; one was multifactorial with exercise and an education component focusing on walking with crutches, bed mobility and postoperative range of movement $^{74}$; and one featured an online educational component alone. ${ }^{80}$

All exercise interventions included strengthening, ${ }^{73-79}$ with additional components targeting gait re-education, ${ }^{74}$ functional exercise, ${ }^{74}{ }^{76}$ improving knee range of movement, flexibility or mobility ${ }^{73} 74 \quad 7677 \quad 79$ and cardiovascular conditioning. ${ }^{73} 7679$ Two studies evaluated a particular manualised programme, 'NEuroMuscular Exercise training program for patients with knee or hip osteoarthritis assigned for total joint replacement' (NEMEX-TJR) ${ }^{81}$ which is described as a series of 


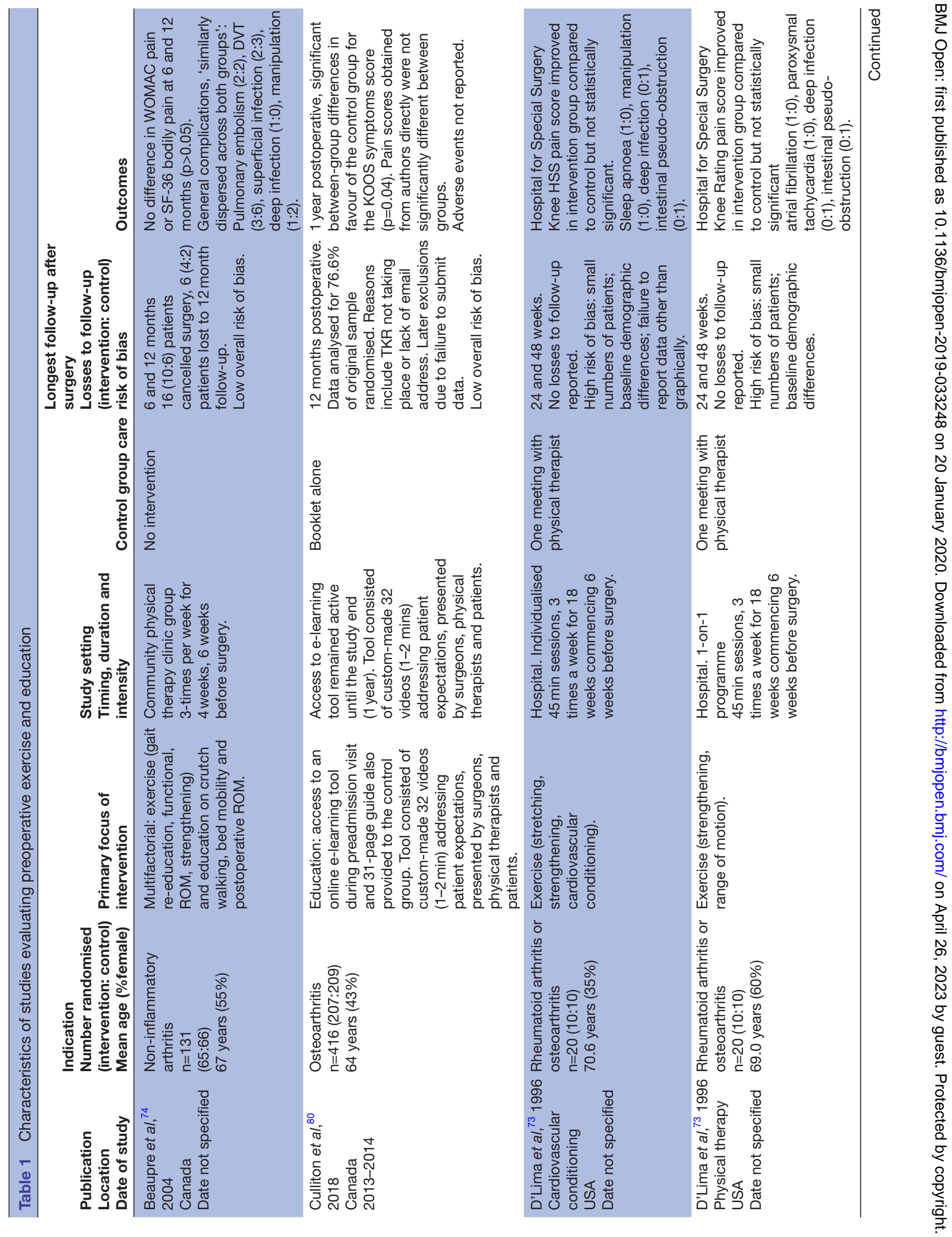




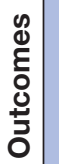
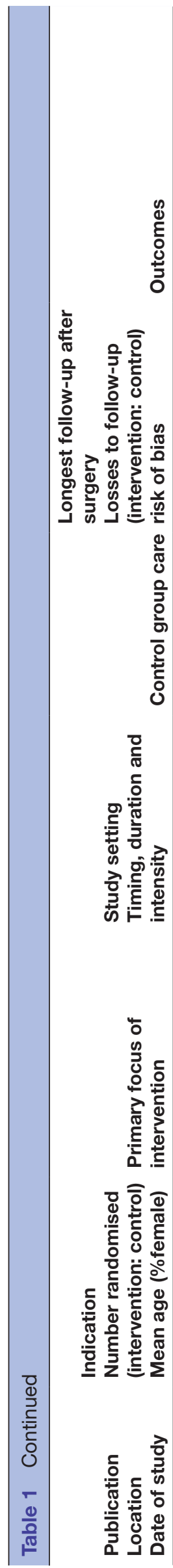
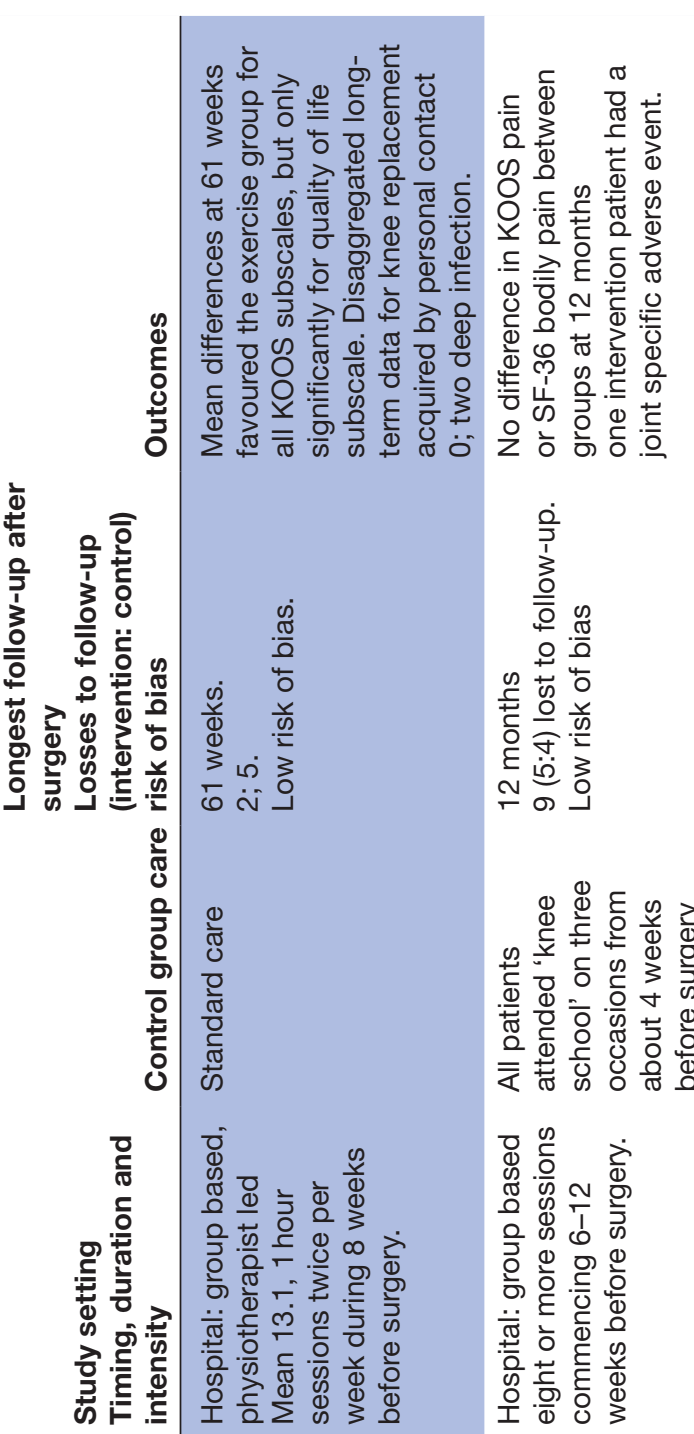
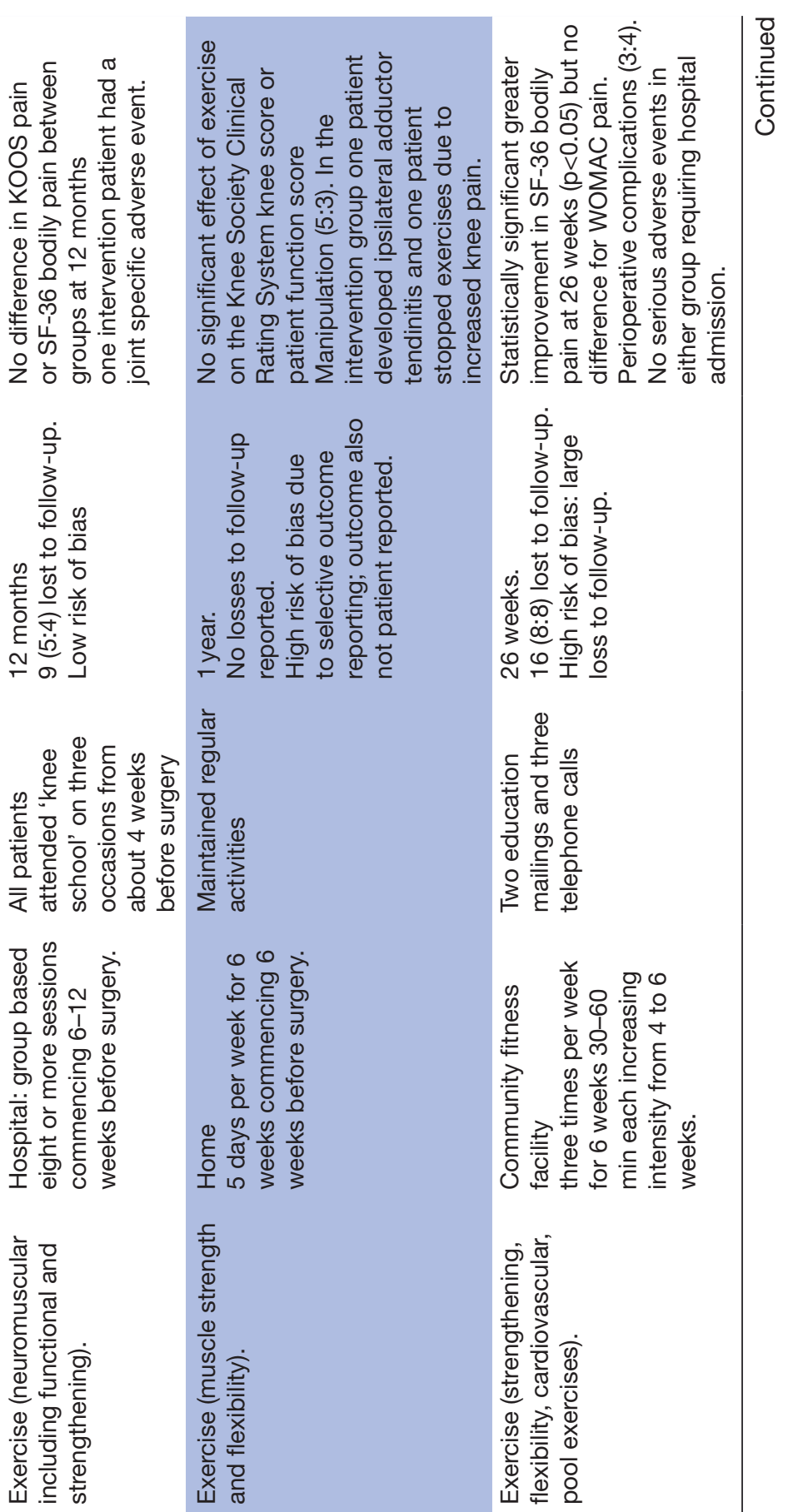

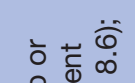

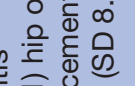

文

कृ

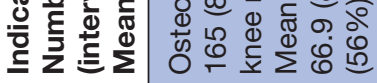

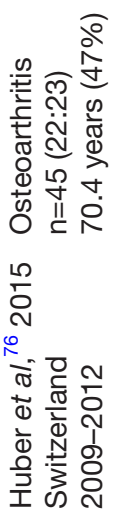

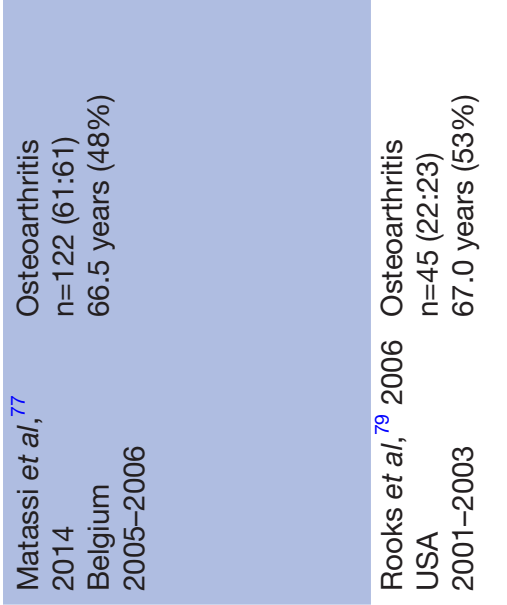



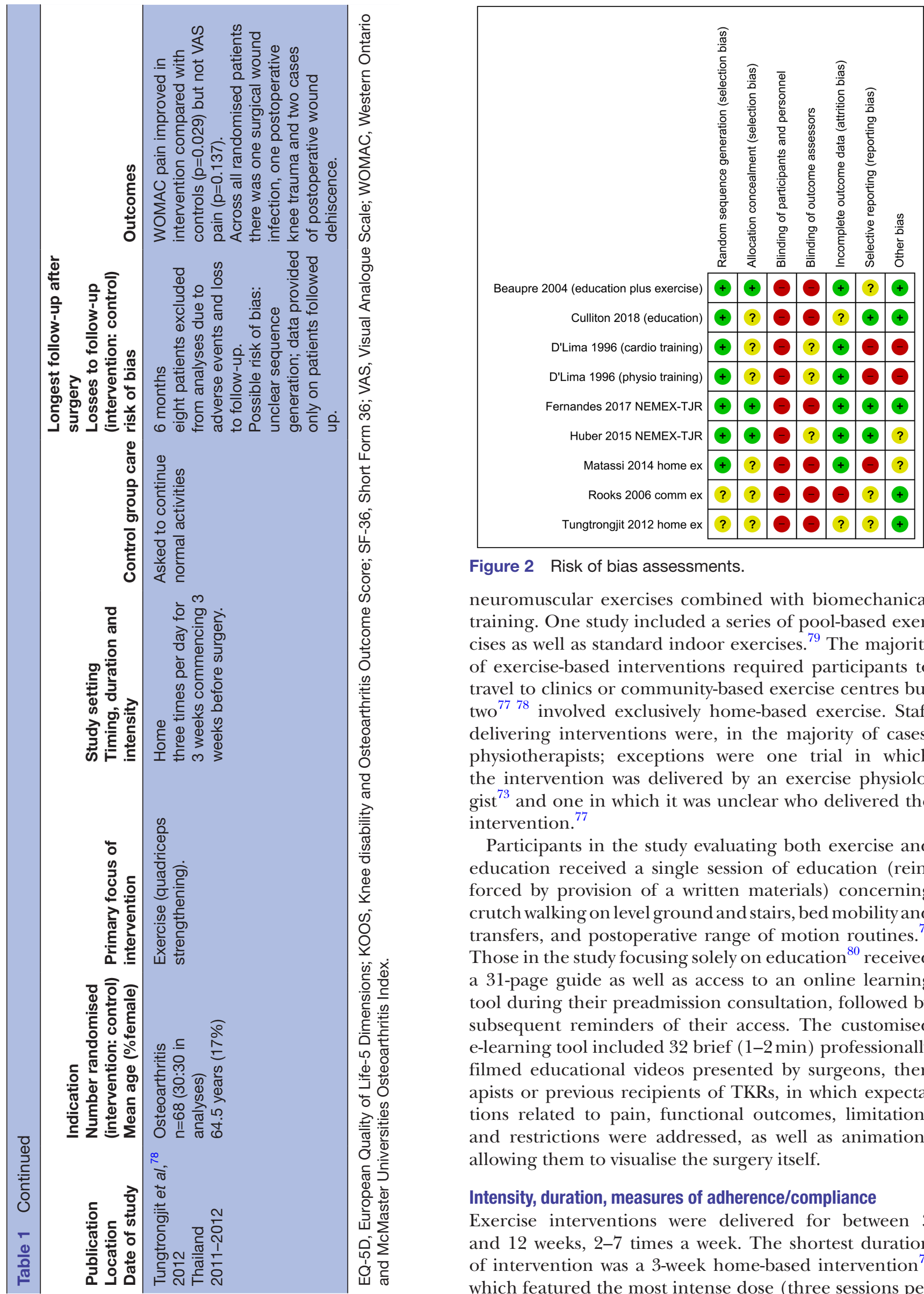

Figure 2 Risk of bias assessments.

neuromuscular exercises combined with biomechanical training. One study included a series of pool-based exercises as well as standard indoor exercises. ${ }^{79}$ The majority of exercise-based interventions required participants to travel to clinics or community-based exercise centres but two ${ }^{77} 78$ involved exclusively home-based exercise. Staff delivering interventions were, in the majority of cases, physiotherapists; exceptions were one trial in which the intervention was delivered by an exercise physiologist $^{73}$ and one in which it was unclear who delivered the intervention. ${ }^{77}$

Participants in the study evaluating both exercise and education received a single session of education (reinforced by provision of a written materials) concerning crutch walking on level ground and stairs, bed mobility and transfers, and postoperative range of motion routines. ${ }^{74}$ Those in the study focusing solely on education ${ }^{80}$ received a 31-page guide as well as access to an online learning tool during their preadmission consultation, followed by subsequent reminders of their access. The customised e-learning tool included 32 brief (1-2 min) professionally filmed educational videos presented by surgeons, therapists or previous recipients of TKRs, in which expectations related to pain, functional outcomes, limitations and restrictions were addressed, as well as animations allowing them to visualise the surgery itself.

\section{Intensity, duration, measures of adherence/compliance}

Exercise interventions were delivered for between 3 and 12 weeks, 2-7 times a week. The shortest duration of intervention was a 3-week home-based intervention ${ }^{78}$ which featured the most intense dose (three sessions per 


\begin{tabular}{|c|c|c|c|c|c|c|c|}
\hline \multirow[b]{2}{*}{ Study or Subgroup } & \multicolumn{3}{|c|}{ Exercise } & \multicolumn{3}{|c|}{ Standard care } & \multirow[b]{2}{*}{ Weight } \\
\hline & Mean & SD & Total & Mean & SD & Total & \\
\hline \multicolumn{8}{|c|}{ 1.1.1 Pain at $6-12$ months (various scales) } \\
\hline D'Lima 1996 (cardio training) & 28.7 & 16.02 & 10 & 27 & 16.02 & 5 & $6.0 \%$ \\
\hline D'Lima 1996 (physio training) & 29 & 16.02 & 10 & 27 & 16.03 & 5 & $6.0 \%$ \\
\hline Rooks 2006 comm ex & -2.4 & 2.7 & 14 & -2.3 & 2 & 15 & $13.0 \%$ \\
\hline Fernandes 2017 NEMEX-TJR & 74.2 & 18.6 & 37 & 73.2 & 21.7 & 37 & $33.3 \%$ \\
\hline Huber 2015 NEMEX-TJR & 87.76 & 11.09 & 17 & 85.95 & 13.39 & 19 & $16.1 \%$ \\
\hline $\begin{array}{l}\text { Tungtrongjit } 2012 \text { home ex } \\
\text { Subtotal }(95 \% \mathrm{Cl})\end{array}$ & -2.5 & 3.1 & $\begin{array}{r}30 \\
118\end{array}$ & -4.8 & 4.2 & $\begin{array}{r}30 \\
111\end{array}$ & $\begin{array}{r}25.7 \% \\
100.0 \%\end{array}$ \\
\hline
\end{tabular}

Test for subaroup differences: Not applicable

Heterogeneity: $\mathrm{Tau}^{2}=0.00 ; \mathrm{Chi}^{2}=3.39, \mathrm{~d}$
Test for overall effect: $Z=1.53(P=0.13)$
Std. Mean Difference

Random, $95 \% \mathrm{Cl}$

$0.10[-0.97,1.17]$

$0.12[-0.96,1.19]$

$-0.04[-0.77,0.69]$

$0.05[-0.41,0.50]$

$0.14[-0.51,0.80]$

$0.62[0.10,1.13]$

$0.20[-0.06,0.47]$

Figure 3 Forest plot: exercise.

day, 7 days a week). The longest period of intervention (8-12 weeks) took place in the two trials ${ }^{75} 76$ delivering the clinic-based NEMEX-TJR intervention. ${ }^{81}$ Here, variability in duration could be determined by how close to the surgery a patient was at time of recruitment.

With regard to exercise interventions conducted within clinics or at home, investigators typically assessed adherence via logbooks ${ }^{74-77}$ recording attendance and sometimes details of achievement and effort. One study of a home-based intervention without formal reporting of adherence featured daily telephone calls to participants ${ }^{78}$; two clinic-based interventions ${ }^{73}$ reported that all participants completed all sessions. The study focussing solely on education ${ }^{80}$ assessed the number of overall 'hits' to different educational videos concerning different aspects of the TKR pathway.

\section{Comparator groups}

Among the trials assessing the effects of exercise or exercise combined with education, detail and nature of comparator groups varied. Five trials described comparator groups as 'usual care'. For three trials the descriptions of usual care were brief but indicated that participants continued with regular activities until surgery. ${ }^{74} 78$ In one trial of cardiovascular exercise, usual care was described as participants having a single meeting with a physiotherapist before their operation for 45 minutes and being provided with printed material about postoperative exercise regimens. ${ }^{73}$ In another trial, usual care involved all participants being offered a 'standard preoperative educational package' comprising written information on the operation, 'expected postoperative progression' and recommended exercises, and a 3-hour in-clinic information session led by health professionals 1 week prior to surgery. ${ }^{75}$

In the two other studies assessing exercise, the comparator groups were designed as attentional controls. In one, participants were sent information on joint replacement, recommended home modifications and on preparing for surgery, reinforced by three telephone calls. ${ }^{79}$ The most intensive control condition was 'knee school' offered alongside an exercise intervention but also offered to the control group participants. ${ }^{76}$ The knee school included formal teaching and peer discussions, was led by an experienced and specially trained physiotherapist over 3 weekly individual or group sessions. Participants were provided with information on anatomy (including photos, diagrams and models), recommended activities after surgery, postoperative pain management and rehabilitation.

In the trial evaluating online education, the control group were provided with a 31-page copy of 'My Guide to Total Knee Joint Replacement' ${ }^{80}$

\section{Outcomes and outcome data}

Six studies reported a joint-specific or condition-specific patient reported pain outcome measure. ${ }^{74-76}$ 78-80 In two publications (one reporting data for two separate comparisons), the outcomes reported were surgeon-assessed. ${ }^{737}$

The latest pain assessment was reported at about 6 months ${ }^{73747677}$ or 12 months after surgery. ${ }^{78-80}$ Measures used were WOMAC pain, ${ }^{7478}$ KOOS pain, ${ }^{760}$ SF-36 bodily pain, ${ }^{74} 7680$ VAS pain, ${ }^{78}$ HSS pain score ${ }^{73}$ and KSS. ${ }^{77}$

We made robust attempts to obtain data through contact with investigators from studies in which data were provided within graphs without $\mathrm{SD},{ }^{73}$ in tables

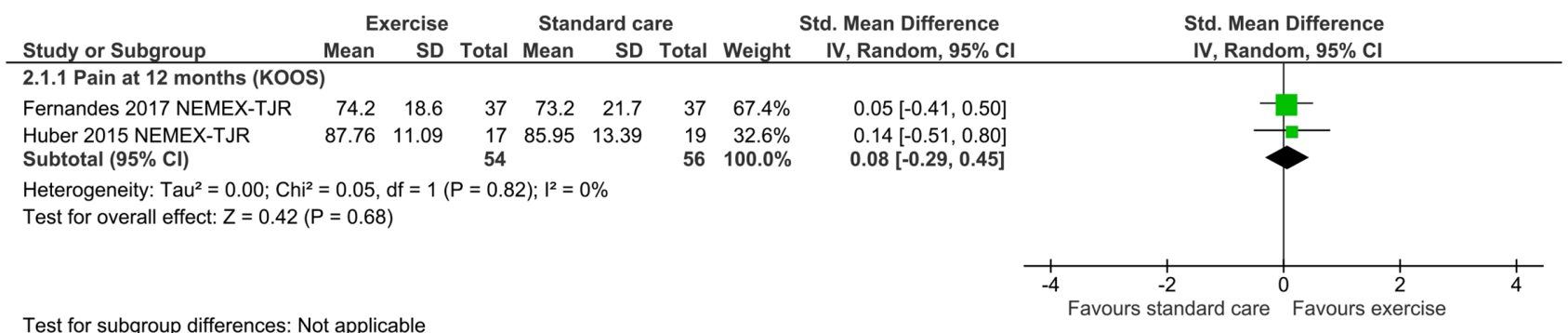

Figure 4 Forest plot: exercise sensitivity analysis. 


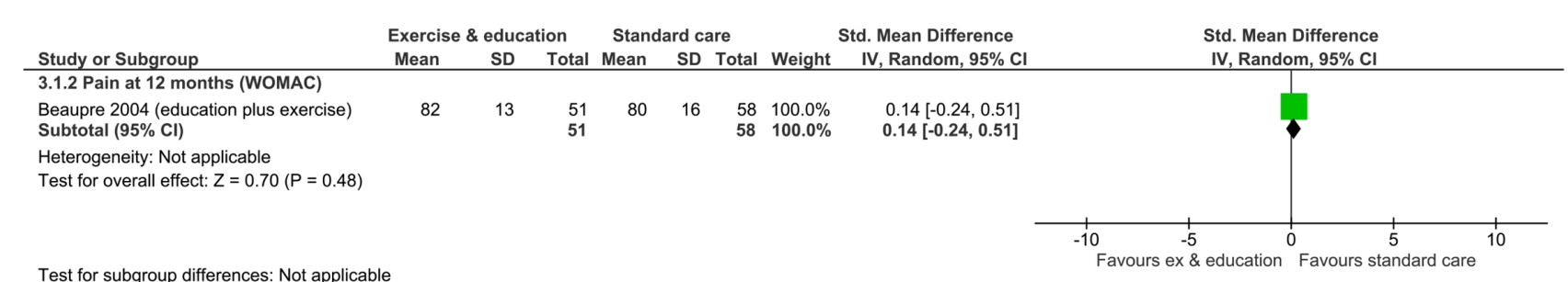

Figure 5 Forest plot: exercise and education.

with means but without $\mathrm{SD}^{80}$ as 'non significant' only ${ }^{77}$ or as part of aggregated hip and knee data. ${ }^{75}$ In three studies, investigators generously provided relevant data in the form of group means and SDs and these data were used. ${ }^{757680}$ Following information that data for one study had been permanently lost, ${ }^{73}$ we measured WOMAC pain data from a graph and, in the absence of SD, used values from a cohort of patients with the same outcome measure reported after TKR but converted from a 50-point to a 30-point scale. ${ }^{82}$ The first author of an exercise-based study which had reported pain findings as simply 'n.s.' (non-significant), responded to our enquiry to indicate that they could no longer access study data.

\section{Risk of bias}

Four studies were assessed as being at an overall low risk of bias. ${ }^{74767780}$ In other studies, we had concerns about potential biases due to differences in baseline patient characteristics in two comparisons ${ }^{73}$ and in one study each, large losses to follow up ${ }^{79}$ and issues regarding sequence generation. $^{78}$

\section{Effects of intervention: exercise alone \\ Pain at 6 months or longer}

Combined results of six eligible interventions reported in five studies ${ }^{73757678} 80$ indicate no clear effect of intervention on long-term pain (SMD $0.20,95 \%$ CI -0.06 to 0.47 ; participants $=229)$. There was no heterogeneity across studies, $\chi^{2}=3.39, \mathrm{I}^{2}=0 \%$ (figure 3 ).

In a sensitivity analysis restricted to two studies with low risk of bias, ${ }^{74}$ group results provided even less suggestion of difference between groups (SMD 0.08, 95\% CI -0.29 to 0.45 ; participants $=110 ; \mathrm{I}^{2}=0 \%$ ) (see figure 4 ).

Results for one study $(\mathrm{n}=122)$ within this category for which no data were suitable for meta-analysis are in line with the results above, with 'non significant' ${ }^{77}$ findings.

\section{Effects of intervention: exercise combined with education}

Pain at 6 months or longer

Results of a single study of exercise with the additional component of one session of education ( $n=109$ followed up) suggest no clear difference between intervention and standard care on long-term pain as assessed by the WOMAC pain scale (MD 2.00, 95\% CI -3.45 to 7.45$)^{74}$ (figure 5).

\section{Effects of intervention: education alone \\ Pain at 6 months or longer}

Results of a single study of education provided by an e-learning tool $(n=319)$ suggest no clear difference between intervention and standard care in terms of longterm pain as assessed on the KOOS (MD -2.55, 95\% CI -6.35 to 1.24$)^{80}$ (figure 6).

\section{Adverse events}

Perisurgical and postsurgical complications including infections were assessed in most studies; see table 1 . Where reported, these do not appear to have differed between groups. Two studies reported presurgical events we judged likely to be intervention-related ${ }^{76} 77$; in each case, participants in an exercise intervention group reported increased pain. No data for this outcome were reported in the study focussing on education alone. ${ }^{80}$

\section{DISCUSSION}

\section{Summary of main findings}

In people with osteoarthritis receiving TKR, the potential value of interventions to manage preoperative risk factors or to target care has frequently been assessed, most often focussing on interventions this review has identified (exercise or 'prehabilitation' and/or education with the aim of managing expectations). We found low-quality to moderate-quality evidence for no effect on our primary

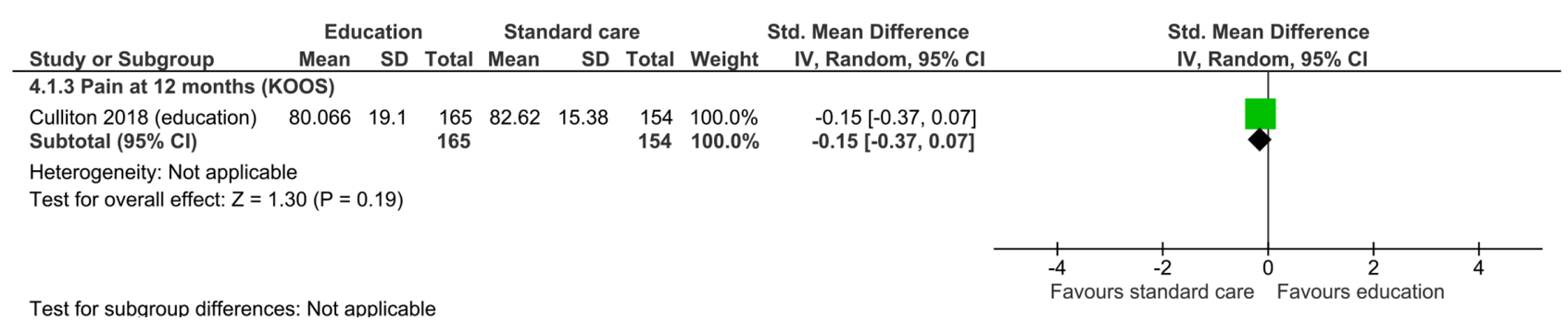

Figure 6 Forest plot: education alone. 


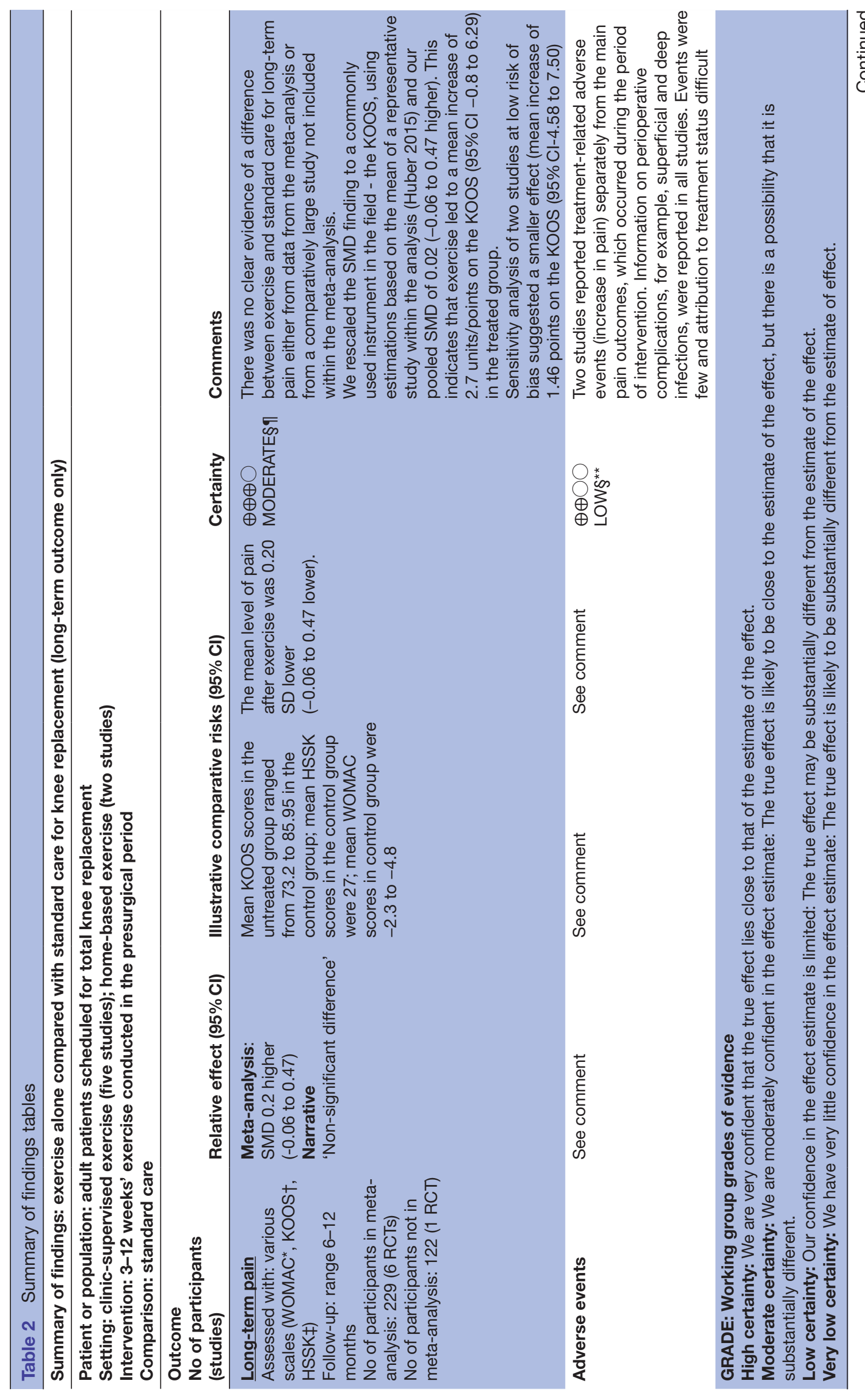




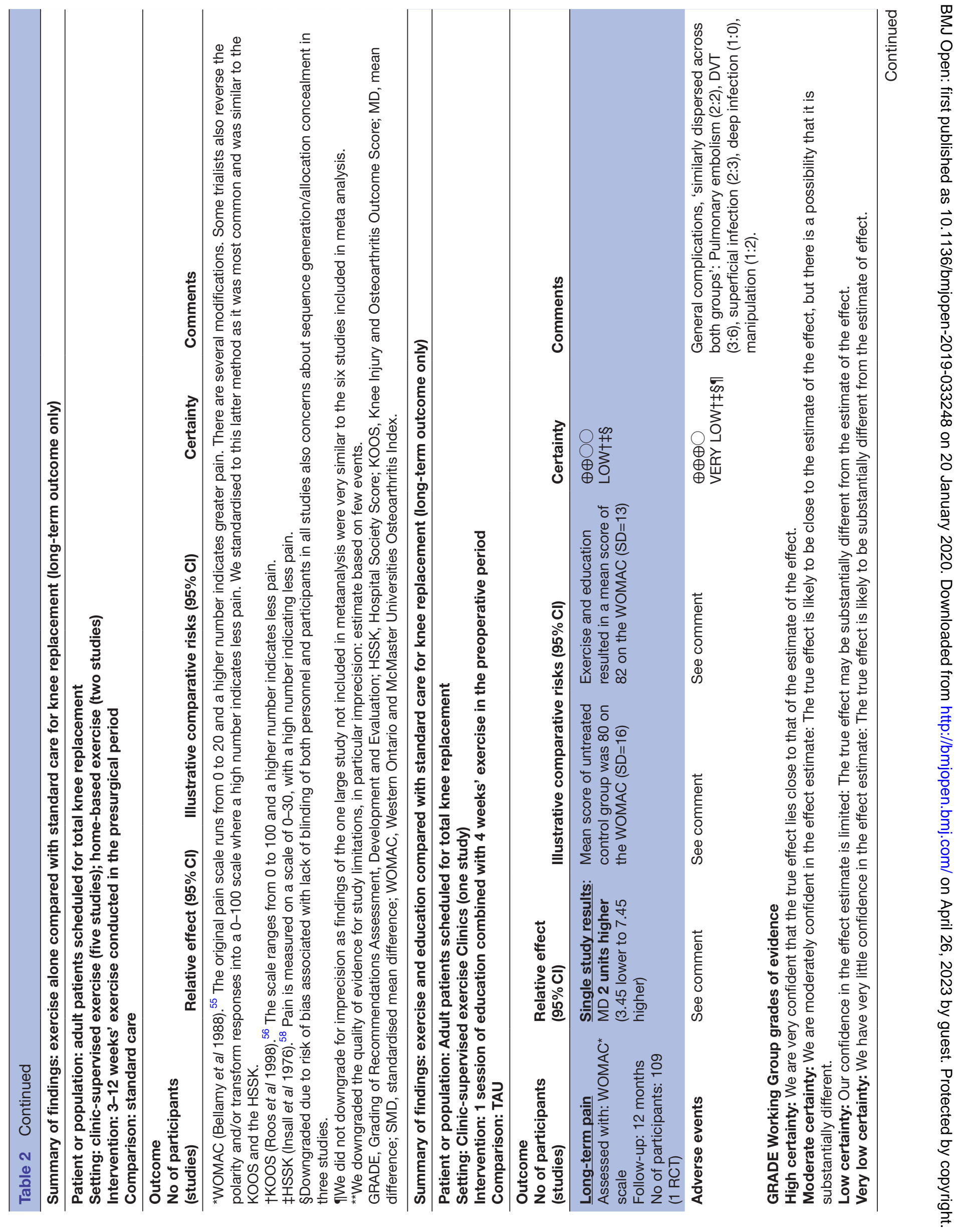




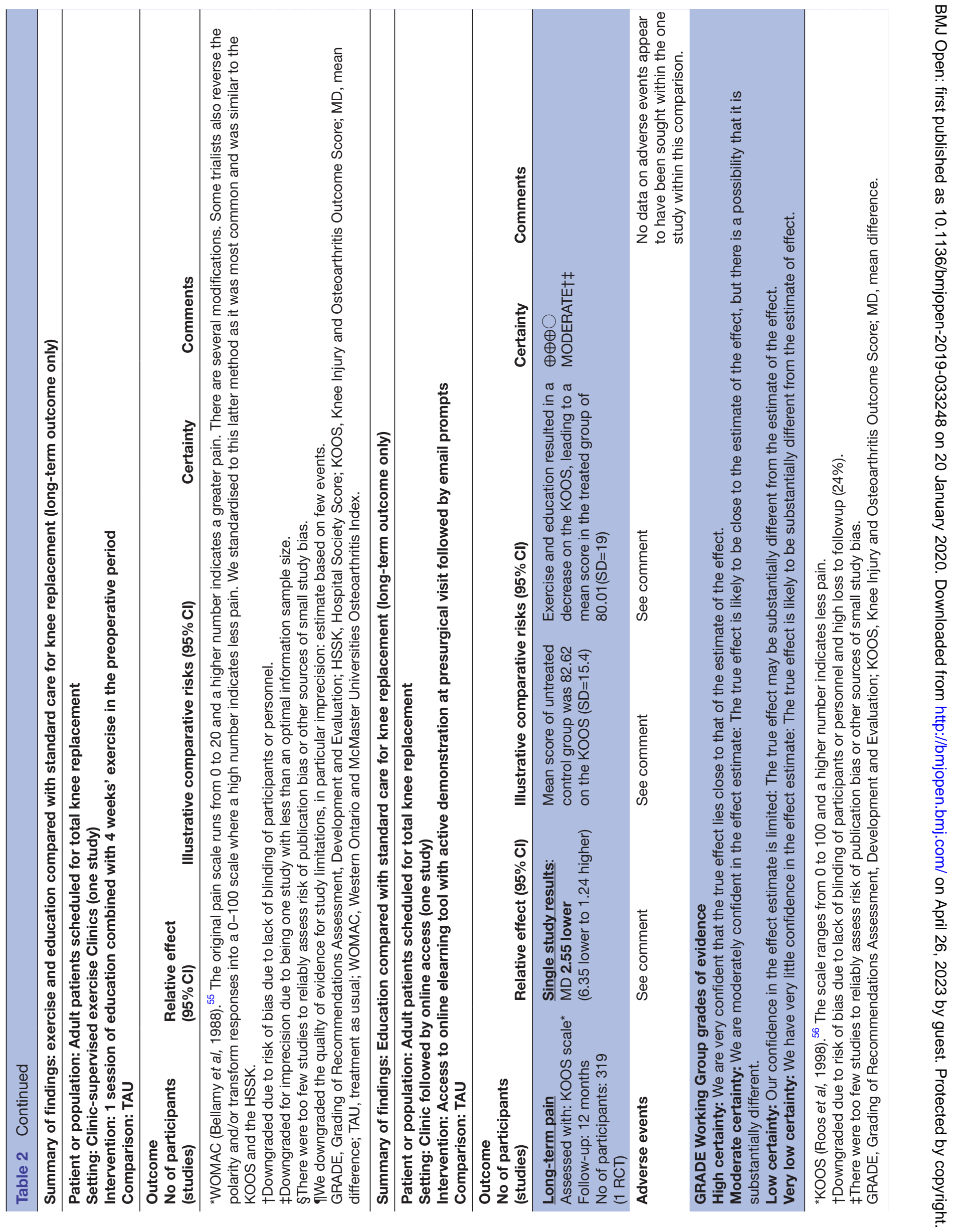


outcome (pain assessed at 6 months or longer) of either exercise, education or education combined with exercise, and we identified no eligible studies assessing the effects of any other eligible preoperative interventions (eg, weight loss programmes or smoking cessation).

\section{Strengths and limitations of this study}

With broad inclusion criteria, we aimed to identify diverse interventions conducted in the preoperative period. Important issues that our review benefits from are preregistration of the study protocol to limit reporting bias, conduct of study according to PRISMA guidelines and comprehensive up to date searches of a range of appropriate literature databases. Experienced systematic reviewers undertook screening of articles, data extraction and risk of bias assessment in duplicate. Author contact was extensive and with the help of study investigators, we included data from studies which had been excluded from previous metaanalyses or had been included with estimates for variances. Furthermore, use of GRADE methodology allowed us to assess the overall quality of the evidence.

A limitation of our review concerns our focus on prevention of long-term pain only. This decision was based on guidelines which emphasise that osteoarthritic pain which is not controlled by conservative treatments is a primary reason that people undergo TKR. ${ }^{83}$ Prevention of long-term pain is a key determinant of patient satisfaction with TKR. ${ }^{84}$ Although the primary outcome of many studies we identified was function, pain severity was an important secondary outcome. We cannot draw conclusions on the value of the interventions we have examined from the point of view of (for example) the benefit to individuals or society of quicker short-term recovery, as proposed by some trialists. ${ }^{75}$

The secondary outcome of this review was adverse events, but reporting was lacking. The poor quality of adverse event reporting in surgical trials is recognised, ${ }^{85}$ and standardisation is required to improve quality and reduce heterogeneity, particularly in orthopaedics. Although patient reported outcomes are frequently considered to be at high risk of bias, we considered them to be appropriate in this review where questionnaires were completed over 6 months after a presurgical intervention.

We also excluded studies in which the intervention continued beyond the period of the TKR procedure; a separate review considering studies including interventions which combined prehabilitation and post-TKR rehabilitation may well be justified.

\section{This review in context}

This is the first review in nearly a decade ${ }^{35}$ which takes as its focus the preoperative period itself, rather than aiming at a class of interventions; the evidence base, however, remains limited.

Previous reviews have focused on outcomes relating to preoperative function and pain, the in-hospital experience and long-term recovery. ${ }^{10} 12-46$ Review conclusions vary based on the outcomes and follow-up times. In general, those concentrating on short-term function and outcomes related to discharge are more likely to report early patient benefit and shorter hospital stay for patients receiving presurgical exercise and education compared with controls. Those considering longer-term postoperative outcomes show little difference in outcomes between randomised groups. One review which evaluated the effects of "prehabilitation' across all surgical patients concluded that "prehabilitation studies are not recommended in patients with osteoarthritis for whom arthroplasty is planned. ${ }^{14}$ Subsequently, among the most comprehensive of systematic reviews conducted in arthroplasty alone is that by Wang and colleagues. ${ }^{46}$ They concluded that the effects of prehabilitation on long-term and indeed many short-term outcomes were too small to be considered clinically important.

Our review adds to the existing evidence base as it includes two trials not included in other reviews ${ }^{7680}$ and previously unreported data from an older trial ${ }^{75}$ which was acquired from study authors. Inclusion of data from these three trials in our meta-analysis did not support use of preoperative exercise or education interventions for the prevention of chronic pain but evidence supporting this was of low to moderate quality. This is in line with previous review conclusions. ${ }^{45}$ Furthermore, a range of preoperative interventions have not been evaluated in randomised trials with long-term follow-up for pain outcome.

\section{Implications for practice and research}

There are several possible explanations for the observed lack of a convincing effect of preoperative interventions on long-term pain after TKR reported within this review. All preoperative interventions conducted within an undifferentiated general population may appear ineffective in the long-term, as for many patients, TKR surgery is highly effective in reducing long-term pain. To detect an effect of intervention for the small but important minority of patients for whom TKR is not highly effective in reducing long-term pain, studies may need either to be much larger, or more focused on particular patient subgroups. Despite the fact that patients report that appropriate and realistic support before surgery can help them achieve a long-term positive experience of surgery, ${ }^{86}$ it is acknowledged that it is difficult to recruit patients to randomised controlled trials before surgery and participants in existing trials may have been highly selected. Patients may have exhausted conservative strategies before surgery and, in evaluating new approaches, there may be an unwillingness among patients to participate in randomised trials. ${ }^{10}$ Intervention content may have focused on improving preoperative physical function and preparing patients for their hospital admission and recovery without specific reference or 'flags' to help identify participants whose recovery did not follow the norm.

An aspect of presurgical health with a possible link with chronic pain is psychological distress. ${ }^{87}$ As an example, pain catastrophising has been implicated as a risk factor for chronic pain. ${ }^{88}$ However, a recent trial where intervention began in the presurgical period and extended well beyond it found that pain coping skills training for 
people with high pain catastrophising did not improve WOMAC pain scores at 12 months after TKR. ${ }^{89}$ Other aspects of preoperative psychological distress are associated with long-term pain after TKR and evaluation of treatment strategies merits investigation. ${ }^{87}$ For other preoperative strategies, such as smoking cessation, weight loss and comorbidity management, there may be tenuous, if any, mechanisms to link with long-term pain outcomes. However, they share a common aim in preparing patients for surgery and preventing adverse events that may limit the potential benefit of knee replacement, so we believe it right to advocate that studies investigating their effects incorporate long-term follow-up.

\section{CONCLUSION}

Presurgical interventions have been evaluated in patients receiving TKR. We found low to moderate-quality evidence to suggest that exercise is not effective in preventing longterm pain in adults scheduled to receive TKR, and it is difficult to recommend further research except of novel approaches and/or in specific populations. The evidence base for education and exercise combined with education was highly limited. However, studies of preoperative interventions with long-term follow-up after surgery are feasible and adequately powered, randomised controlled trials, planned and reported according to Consolidated Standards of Reporting Trials standards, should be conducted to identify clinically effective preoperative treatments to help patients achieve a long-term pain-free outcome after knee replacement.

Acknowledgements We gratefully acknowledge unpublished outcome data from the following investigators: Dr Sharon Culliton, Dr Erika Huber and Dr Allan Villadsen. We also are thankful for confirmation concerning other study data from Professor Darryl D'Lima and Dr Fabrizio Matassi. We are also thankful for translation of Yunfei Li, University of Bristol, for his help in translating a paper from Chinese.

Contributors All authors contributed to the concept and design of the study. JD, $A D B$ and VW contributed to the acquisition and analysis of data. JD and ADB drafted the article and VW, RG-H and AWB revised it critically for important intellectual content. JD and ADB take responsibility for the integrity of the work as a whole, from inception to finished article.

Funding This study is funded by the National Institute for Health Research (NIHR) [NIHR Programme Grant for Applied Research (Grant Reference Number RP-PG0613-20001)]. This study was also supported by the NIHR Biomedical Research Centre at the University Hospitals Bristol NHS Foundation Trust and the University of Bristol. The views expressed in this publication are those of the authors and not necessarily those of the NHS, the National Institute for Health Research or the Department of Health and Social Care.

Disclaimer The views expressed are those of the authors and not necessarily those of the NHS, the NIHR or the Department of Health. The funder had no involvement in the study design, data collection, data analysis, interpretation of data or writing of the manuscript.

Competing interests Outside of this work, VW and AWB are c0-applicants on an institutional grant from Stryker for a study evaluating the outcomes of the Triathlon knee replacement.

Patient consent for publication Not required.

Provenance and peer review Not commissioned; externally peer reviewed.

Data availability statement No data are available. All data relevant to the study are included in the article or uploaded as supplementary information.
Open access This is an open access article distributed in accordance with the Creative Commons Attribution 4.0 Unported (CC BY 4.0) license, which permits others to copy, redistribute, remix, transform and build upon this work for any purpose, provided the original work is properly cited, a link to the licence is given, and indication of whether changes were made. See: https://creativecommons.org/ licenses/by/4.0/.

ORCID iDs

Jane Dennis http://orcid.org/0000-0001-9718-2653

Andrew David Beswick http://orcid.org/0000-0002-7032-7514

\section{REFERENCES}

1 McAlindon TE, Bannuru RR, Sullivan MC, et al. OARSI guidelines for the non-surgical management of knee osteoarthritis. Osteoarthritis Cart 2014;22:363-88.

2 National Institute for Health and Clinical Excellence. Osteoarthritis: care and management. London, 2014.

3 NJR Centre. National Joint Registry for England, Wales, Northern Ireland and the Isle of Man: 15th annual report. Hemel Hempstead, 2018.

4 Scottish Arthroplasty Project. Annual report 2018. Edinburgh: NHS National Services Scotland, 2018.

5 Maradit Kremers H, Larson DR, Crowson CS, et al. Prevalence of total hip and knee replacement in the United States. J Bone Joint Surg Am 2015;97:1386-97.

6 Beswick AD, Wylde V, Gooberman-Hill R, et al. What proportion of patients report long-term pain after total hip or knee replacement for osteoarthritis? A systematic review of prospective studies in unselected patients. BMJ Open 2012;2:e000435.

7 Nilsdotter AK, Toksvig-Larsen S, Roos EM. Knee arthroplasty: are patients' expectations fulfilled? A prospective study of pain and function in 102 patients with 5-year follow-up. Acta Orthop 2009;80:55-61.

8 Scott CE, Howie CR, MacDonald D, et al. Predicting dissatisfaction following total knee replacement: a prospective study of 1217 patients. J Bone Joint Surg 2010;92:1253-8.

9 Sayers A, Wylde V, Lenguerrand E, et al. Rest pain and movementevoked pain as unique constructs in hip and knee replacements. Arthritis Care Res 2016;68:237-45.

10 Blom AW, Artz N, Beswick AD, et al. Improving patients' experience and outcome of total joint replacement: the RESTORE programme. Programme Grants Appl Res 2016:4:1-508.

11 Wylde V, Beswick A, Bruce J, et al. Chronic pain after total knee arthroplasty. EFORT Open Rev 2018;3:461-70.

12 Ackerman IN, Bennell KL. Does pre-operative physiotherapy improve outcomes from lower limb joint replacement surgery? A systematic review. Aust J Physiother 2004;50:25-30.

13 Bock M, Johansson T, Fritsch G, et al. The impact of preoperative testing for blood glucose concentration and haemoglobin A1c on mortality, changes in management and complications in noncardiac elective surgery. Eur J Anaesthesiol 2015;32:152-9.

14 Cabilan CJ, Hines S, Munday J. The effectiveness of prehabilitation or preoperative exercise for surgical patients: a systematic review. JBI Database System Rev Implement Rep 2015;13:146-87.

15 Cheatham SW. Do patient factors and prehabilitation improve outcomes after total knee arthroplasty? Top Geriatr Rehabil 2013;29:17-24.

16 Coudeyre E, Jardin C, Givron P, et al. Could preoperative rehabilitation modify postoperative outcomes after total hip and knee arthroplasty? Elaboration of French clinical practice guidelines. Annales de Réadaptation et de Médecine Physique 2007;50:189-97.

17 Dauty M, Genty M, Ribinik P. Physical training in rehabilitation programs before and after total hip and knee arthroplasty. Annales de Réadaptation et de Médecine Physique 2007;50:462-8.

18 Ellerby N, Hider S, Mallen C, et al. 195. Does Intra-Articular Corticosteroid Injection in the Pre-Operative Period Increase the Risk of Joint Infection Following Hip or Knee Arthroplasty? A Systematic Review and Meta-Analysis. Rheumatology 2014;53:i132.

19 Gawel JA, Brown SE, Collins JC, et al. Does pre-operative physical therapy improve post-surgical outcomes of patients undergoing a total knee and/or total hip arthroplasty? A systematic review. Physiother Pract Res 2013;34:9-20.

20 Gill SD, McBurney H. Does exercise reduce pain and improve physical function before hip or knee replacement surgery? A systematic review and meta-analysis of randomized controlled trials. Arch Phys Med Rehabil 2013;94:164-76.

21 Hoogeboom TJ, Oosting E, Vriezekolk JE, et al. Therapeutic validity and effectiveness of preoperative exercise on functional recovery 
after joint replacement: a systematic review and meta-analysis. Nederlands Tijdschrift Voor Fysiotherapie 2012;122:150-60.

22 Johansson K, Nuutila L, Virtanen H, et al. Preoperative education for orthopaedic patients: systematic review. J Adv Nurs 2005;50:212-23.

23 Jordan RW, Smith NA, Chahal GS, et al. Enhanced education and physiotherapy before knee replacement; is it worth it? A systematic review. Physiotherapy 2014;100:305-12.

24 Louw A, Diener I, Butler DS, et al. Preoperative education addressing postoperative pain in total joint arthroplasty: review of content and educational delivery methods. Physiother Theory Pract 2013;29:175-94.

25 Lucas B. Does a pre-operative exercise programme improve mobility and function post-total knee replacement: a mini-review. J Orthop Nurs 2004;8:25-33.

26 Mak JCS, Fransen M, Jennings M, et al. Evidence-Based review for patients undergoing elective hip and knee replacement. ANZ J Surg 2014;84:17-24.

27 McDonald S, Page MJ, Beringer K, et al. Preoperative education for hip or knee replacement. Cochrane Database Syst Rev 2014:5:CD003526.

28 Santa Mina D, Clarke H, Ritvo P, et al. Effect of total-body prehabilitation on postoperative outcomes: a systematic review and meta-analysis. Physiotherapy 2014;100:196-207.

29 Sau-Man Conny C, Wan-Yim I. The effectiveness of nurse-led preoperative assessment clinics for patients receiving elective orthopaedic surgery: a systematic review. J Perianesth Nurs 2016;31:465-74.

30 Shoemaker MJ, Gibson C, Saagman S. Preoperative exercise in individuals undergoing total knee arthroplasty. Top Geriatr Rehabil 2013;29:2-16.

31 Silkman Baker C, McKeon JM. Does preoperative rehabilitation improve patient-based outcomes in persons who have undergone total knee arthroplasty? A systematic review. PM\&R 2012;4:756-67.

32 Simmons L, Smith T. Effectiveness of pre-operative physiotherapybased programmes on outcomes following total knee arthroplasty: a systematic review and meta-analysis. Phys Ther Rev 2013;18:1-10.

33 Skoffer B, Dalgas U, Mechlenburg I. Progressive resistance training before and after total hip and knee arthroplasty: a systematic review. Clin Rehabil 2015;29:14-29.

34 Valkenet K, van de Port IGL, Dronkers JJ, et al. The effects of preoperative exercise therapy on postoperative outcome: a systematic review. Clin Rehabil 2011;25:99-111.

35 Wallis JA, Taylor NF. Pre-Operative interventions (non-surgical and non-pharmacological) for patients with hip or knee osteoarthritis awaiting joint replacement surgery - a systematic review and metaanalysis. Osteoarthritis Cart 2011;19:1381-95.

36 Aydin D, Klit J, Jacobsen S, et al. No major effects of preoperative education in patients undergoing hip or knee replacement--a systematic review. Dan Med J 2015;62:A5106.

37 Bay S, Kuster L, McLean N, et al. A systematic review of psychological interventions in total hip and knee arthroplasty. BMC Musculoskelet Disord 2018;19:201.

38 Chen H, Li S, Ruan T, et al. Is it necessary to perform prehabilitation exercise for patients undergoing total knee arthroplasty: metaanalysis of randomized controlled trials. Phys Sportsmed 2018;46:36-43.

39 Kwok IHY, Paton B, Haddad FS. Does pre-operative physiotherapy improve outcomes in primary total knee arthroplasty? - a systematic review. J Arthroplasty 2015;30:1657-63.

40 Ma J-X ZL-K, Kuang M-J, Zhao J, et al. The effect of preoperative training on functional recovery in patients undergoing total knee arthroplasty: a systematic review and meta-analysis. Int J Surg 2018;51:205-12.

41 Peer M, Rush R, Gallacher P, et al. Pre-surgery exercise and postoperative physical function of people undergoing knee replacement surgery: a systematic review and meta-analysis of randomized controlled trials. J Rehabil Med 2017;49:304-15.

42 Umehara T, Tanaka R. Effective exercise intervention period for improving body function or activity in patients with knee osteoarthritis undergoing total knee arthroplasty: a systematic review and meta-analysis. Braz J Phys Ther 2018;22:265-75.

43 Zhang H, Hao X, Shuai T, et al. Efficacy of preoperative rehabilitation for total knee replacement: a systematic review. Chinese Journal of Evidence-Based Medicine 2017;17:1060-5.

44 Zhao $\mathrm{Y}$, Jiang $\mathrm{C}$, Peng $\mathrm{H}$, et al. The effectiveness and safety of preoperative use of erythropoietin in patients scheduled for total hip or knee arthroplasty: a systematic review and meta-analysis of randomized controlled trials. Medicine 2016;95:e4122.

45 Chesham RA, Shanmugam S. Does preoperative physiotherapy improve postoperative, patient-based outcomes in older adults who have undergone total knee arthroplasty? A systematic review. Physiother Theory Pract 2017;33:9-30.

46 Wang L, Lee M, Zhang Z, et al. Does preoperative rehabilitation for patients planning to undergo joint replacement surgery improve outcomes? A systematic review and meta-analysis of randomised controlled trials. BMJ Open 2016;6:e009857.

47 Wylde V, Dennis J, Gooberman-Hill R, et al. Effectiveness of postdischarge interventions for reducing the severity of chronic pain after total knee replacement: systematic review of randomised controlled trials. BMJ Open 2018;8:e020368.

48 Beswick AD, Dennis J, Gooberman-Hill R, et al. Are perioperative interventions effective in preventing chronic pain after primary total knee replacement? A systematic review. BMJ Open 2019;9:e028093.

49 Beswick A, Dennis J, Gooberman-Hill R, et al. The effectiveness of pre-, peri- and post-operative interventions in preventing chronic pain in patients receiving primary total knee replacement: a systematic review. Prospero, 2017.

50 Richardson WS, Wilson MC, Nishikawa J, et al. The well-built clinical question: a key to evidence-based decisions. ACP J Club 1995:123:A12-13.

51 Higgins JPT, Green S. Cochrane Handbook for Systematic Reviews of Interventions Version 5.1.0 [Updated March 2011]: The Cochrane Collaboration, 2011. Available: http://www.cochrane-handbook.org

52 Moher D, Liberati A, Tetzlaff J, et al. Preferred reporting items for systematic reviews and meta-analyses: the PRISMA statement. $J$ Clin Epidemiol 2009;62:1006-12.

53 Gooberman-Hill R, Burston A, Clark E, et al. Involving patients in research: considering good practice. Musculoskeletal Care 2013;11:187-90.

54 Murray DW, Fitzpatrick R, Rogers $\mathrm{K}$, et al. The use of the Oxford hip and knee scores. J Bone Joint Surg Br 2007;89-B:1010-4

55 Bellamy N, Buchanan W, Goldsmith C, et al. Validation study of WOMAC: a health status instrument for measuring clinicallyimportant patient-relevant outcomes following total hip or knee arthroplasty in osteoarthritis. J Orthop Rheumatol 1988;15:1833-40.

56 Roos EM, Roos HP, Lohmander LS, et al. Knee Injury and Osteoarthritis Outcome Score (KOOS)-Development of a SelfAdministered Outcome Measure. J Orthop Sports Phys Ther 1998;28:88-96.

57 Insall JN, Dorr LD, Scott RD, et al. Rationale of the knee Society clinical rating system. Clin Orthop Relat Res 1989;248:13-14.

58 Insall JN, Ranawat CS, Aglietti P, et al. A comparison of four models of total knee-replacement prostheses. J Bone Joint Surg (Am) 1976;58:754-65.

59 Wylde V, Bruce J, Beswick A, et al. Assessment of chronic postsurgical pain after knee replacement: a systematic review. Arthritis Care Res 2013;65:1795-803.

60 Hewlett SA. Patients and clinicians have different perspectives on outcomes in arthritis. J Rheumatol 2003;30:877-9.

61 Bachmeier CJM, March LM, Cross MJ, et al. A comparison of outcomes in osteoarthritis patients undergoing total hip and knee replacement surgery. Osteoarthritis Cart 2001;9:137-46.

62 Ware JE, Sherbourne CD. The mos 36-item short-form health survey (SF-36). I. conceptual framework and item selection. Med Care 1992;30:473-83.

63 Ware J, Kosinski M, Keller SD. A 12-Item short-form health survey: construction of scales and preliminary tests of reliability and validity. Med Care 1996;34:220-33.

64 Dworkin RH, Turk DC, Farrar JT, et al. Core outcome measures for chronic pain clinical trials: IMMPACT recommendations. Pain 2005;113:9-19.

65 Moore AR, Eccleston C, Derry S, et al. "Evidence" in chronic pain establishing best practice in the reporting of systematic reviews. Pain 2010;150:386-9.

66 Higgins JPT, Altman DG, Gøtzsche PC, et al. The Cochrane collaboration's tool for assessing risk of bias in randomised trials. BMJ 2011;343:d5928.

67 The Cochrane Collaboration. Review Manager (RevMan) [Computer program]. Version 5.3. Copenhagen: The Nordic Cochrane Centre, 2014.

68 Guyatt G, Oxman AD, Akl EA, et al. Grade guidelines: 1. Introduction-GRADE evidence profiles and summary of findings tables. J Clin Epidemiol 2011:64:383-94.

69 Villebro NM, Pedersen T, Møller AM, et al. Long-Term effects of a preoperative smoking cessation programme. Clin Respir $J$ 2008;2:175-82.

70 Amory JK, Chansky HA, Chansky KL, et al. Preoperative supraphysiological testosterone in older men undergoing knee replacement surgery. J Am Geriatr Soc 2002;50:1698-701.

71 Moonen A, Thomassen BJW, Knoors NT, et al. Pre-operative injections of epoetin-alpha versus post-operative retransfusion 
of autologous shed blood in total hip and knee replacement: a prospective randomised clinical trial. J Bone Joint Surg 2008;90:1079-83.

72 Sousa RJG, Barreira PMB, Leite PTS, et al. Preoperative Staphylococcus aureus Screening/Decolonization protocol before total joint Arthroplasty - Results of a small prospective randomized trial. J Arthroplasty 2016;31:234-9.

73 D'Lima DD, Colwell CW, Morris BA, et al. The effect of preoperative exercise on total knee replacement outcomes. Clin Orthop Relat Res 1996;326:174-82.

74 Beaupre LA, Lier D, Davies DM, et al. The effect of a preoperative exercise and education program on functional recovery, health related quality of life, and health service utilization following primary total knee arthroplasty. J Rheumatol 2004;31:1166-73.

75 Fernandes L, Roos EM, Overgaard S, et al. Supervised neuromuscular exercise prior to hip and knee replacement: 12-month clinical effect and cost-utility analysis alongside a randomised controlled trial. BMC Musculoskelet Disord 2017;18:5.

76 Huber EO, Roos EM, Meichtry A, et al. Effect of preoperative neuromuscular training (NEMEX-TJR) on functional outcome after total knee replacement: an assessor-blinded randomized controlled trial. BMC Musculoskelet Disord 2015;16:101.

77 Matassi F, Duerinckx J, Vandenneucker H, et al. Range of motion after total knee arthroplasty: the effect of a preoperative home exercise program. Knee Surg Sports Traumatol Arthrosc 2014;22:703-9.

78 Tungtrongjit Y, Weingkum P, Saunkool P. The effect of preoperative quadriceps exercise on functional outcome after total knee arthroplasty. J Med Assoc Thai 2012;95:S58-66.

79 Rooks DS, Huang J, Bierbaum BE, et al. Effect of preoperative exercise on measures of functional status in men and women undergoing total hip and knee arthroplasty. Arthritis Rheum 2006;55:700-8.

80 Culliton SE, Bryant DM, MacDonald SJ, et al. Effect of an elearning tool on expectations and satisfaction following total knee arthroplasty: a randomized controlled trial. J Arthroplasty 2018;33:2153-8.

81 Ageberg E, Link A, Roos EM. Feasibility of neuromuscular training in patients with severe hip or knee oa: the individualized goalbased NEMEX-TJR training program. BMC Musculoskelet Disord 2010;11:126.

82 Jacobs CA, Christensen CP. Correlations between knee Society function scores and functional force measures. Clin Orthop Relat Res 2009;467:2414-9.

83 Gademan MGJ, Hofstede SN, Vliet Vlieland TPM, et al. Indication criteria for total hip or knee arthroplasty in osteoarthritis: a state-of-the-science overview. BMC Musculoskelet Disord 2016;17:463.

84 Hamilton DF, Lane JV, Gaston P, et al. What determines patient satisfaction with surgery? A prospective cohort study of 4709 patients following total joint replacement. BMJ Open 2013;3:e002525.

85 Wylde V, Dennis J, Beswick AD, et al. Systematic review of management of chronic pain after surgery. Br J Surg 2017;104:1293-306.

86 Goldsmith LJ, Suryaprakash N, Randall E, et al. The importance of informational, clinical and personal support in patient experience with total knee replacement: a qualitative investigation. BMC Musculoskelet Disord 2017;18:127.

87 Sorel JC, Veltman ES, Honig A, et al. The influence of preoperative psychological distress on pain and function after total knee arthroplasty: a systematic review and meta-analysis. Bone Joint $J$ 2019;101-B:7-14.

88 Edwards RR, Haythornthwaite JA, Smith MT, et al. Catastrophizing and depressive symptoms as prospective predictors of outcomes following total knee replacement. Pain Res Manag 2009;14:307-11.

89 Riddle DL, Keefe FJ, Ang DC, et al. Pain coping skills training for patients who catastrophize about pain prior to knee arthroplasty: a multisite randomized clinical trial. J Bone Joint Surg 2019;101:218-27. 